\title{
CONVERSATION AS INQUIRY: A CONVERSATION WITH INSTRUCTIONAL DESIGNERS
}

\author{
Katy Campbell \\ Faculty of Extension \\ University of Alberta, CANADA \\ katy.campbell@ualberta.ca \\ Richard A. Schwier \\ Educational Communications and Technology \\ University of Saskatchewan, CANADA \\ richard.schwier@usask.ca \\ Richard F. Kenny \\ Centre for Distance Education \\ Athabasca University, CANADA \\ rickk@athabascau.ca
}

\begin{abstract}
Instructional designers regularly engage in a process of professional and personal transformation that has the potential to transform the culture of institutions through faculty-client relationships. Instructional designers promote new ideas and understandings in social contexts that include other designers and clients, among others. This research program attempts to understand this process, using narrative inquiry and instructional designers' stories of practice to explore two interconnected theoretical frames. One frame is methodological and offers a case for narrative inquiry as an alternative approach to research in educational technology. The second frame is practice-based, and uses narrative inquiry to explore the themes of reflexivity, voice, strong subjectivity and power/authority through the stories of three instructional designers.
\end{abstract}

Keywords

Instructional design, narrative inquiry, conversation, educational technology, instructional designers, critical theory, agency, moral authority

\section{Introduction}

I collect menus from restaurants when I travel; they elicit memories in the way that photos or postcards do not. Eating in the company of my traveling companions is an intimate experience. When I re-read the menu I remember the tastes and smells of my meal, murmurs of the muted busyness of the restaurant - people talking, dishes and pots clinking, soft music — the feel of the sunshine on the patio or the candles in a tiny bistro, how my meal first looked on my plate, sharing bites with my partner; the conversation that recalled the experiences of the day, already shaped in memory by time and reflection. Evoked again when I catch a whiff of the sour fresh bread or roasting garlic, or hear a snatch of the same music; my memories are framed by these senses. 
When I frame the menu and hang it in my dining room I choose a particular section, a certain page; I might add a coloured mat to frame a title, or an image. We choose frames to tell us what we need to look at in a picture, what is personally significant; what we want to share. ${ }^{1}$

As instructional designers in higher education institutions, we live within embedded frames that define our missions, goals, and practices. What are these frames? What images fill these frames and who is involved in creating them? If one frame replaces another, how does the focus change? As instructional designers and researchers of instructional design we have been exploring this idea of frames as a problem of practice. We believe that instructional designers are creators of meaningful images within frames that reflect constantly interacting personal, professional, institutional, and social visions and goals. These frames are described and mediated through a series of conversations - with our personal and professional histories, our discipline, our colleagues, our clients, our institutional and cultural contexts and, most importantly, our values. We believe that there is a reciprocal relationship between design and conversation: conversation is design, and design emerges through conversation. Further, as we live our personal/professional lives in a series of conversations we believe that we can understand our practice through a series of constant collaborative conversations with designers. But we know that conversation is not always deliberate, nor do instructional designers always reflect deeply on conversations they have. Therefore, it was an intention of our research to have conversations with designers that are deliberate and that encourage deep reflection about their purpose and practice.

We have said elsewhere (c.f. Campbell, Gibson, \& Gramlich, 2005; Campbell, Schwier, \& Kenny, 2005) that through their work with others instructional designers engage in a process of professional and personal transformation that has the potential to transform the institution through faculty-client relationships. We accept that learning involves shared thinking or understanding and is most effective if embedded in social experience and situated in authentic problem-solving contexts (cf. Glaser, 1991; Jonassen, Dyer, Peters, Robinson, Harvey, King, \& Loughner, 1997; Rogoff, 1990). The instructional design process is rarely played out in social isolation; instead designers and others develop new ideas and understandings in social contexts. This may be a form of cultural learning or collaborative learning for those engaged in the interaction: designers, faculty, administrators, technical staff, and students. Exploiting the metaphor of instructional design as conversation has implications for both personal and social action. Understanding this process through conversation has implications for both professional and methodological change in our field.

In this paper we offer instructional designers' stories of practice through which we explore two interconnected theoretical frames using four lenses: reflexivity, voice, strong objectivity, and power/authority. These lenses themselves are woven together by the idea of moral action. One frame is methodological (that is, conversation as inquiry), a case for narrative inquiry as an alternative frame for research in educational technology; and the other is practice-based (that is, instructional design as conversation). The stories are drawn from the data set of 49 research conversations with more than twenty instructional designers in higher education institutions in Canada. This was part of a three-year study funded by the Social Sciences and Humanities Research Council. There are several purposes for this study and its products. As a reflexive project we share our stories as practitioners and, as conversational partners and in community, 'reformulate our conceptions of identity and self-hood' (Goodson, 1995, p. 3). This is one of a series of completed and developing papers that will explore identity, social action and community and challenge us to think about instructional design research in alternative ways. Ultimately, even though much continues to be written about the effect of technology and computers on society, designers do not necessarily see their agency in the development of a knowledge economy that reflects culturally biased views of teaching, learning, and the construction of knowledge.

\footnotetext{
${ }^{1}$ In her OPAS' Visionary Seminar on November 8, 2004, Pamela Wallin, Canada’s Ambassador to New York, used the metaphor of frames to explore Canadian/American sociopolitical relationships.
} 
We believe that instructional designers have not been encouraged to examine their cultural values and assumptions critically, and we wanted to challenge the idea that the expert knowledge of designers, gained through education, experience and interaction, should remain unexamined.

\section{The Research Study}

The stories reported in this article were drawn from a three-year (2002-2005) study involving six Canadian universities and smaller institutions of higher education. The participating institutions have an administrative and/or academic unit whose mandate is to support faculty developing (usually) technology-enhanced, 'blended', or online learning environments. Initially, we selected participants using criteria established by the annual MacLean’s Magazine criteria for ranking Canadian Universities, that is, we targeted institutions in the first peer group, the Medical Doctoral Universities, those with a broad range of $\mathrm{PhD}$ programs and research, as well as medical schools. The participating institutions had an administrative and/or academic unit that employed at least two instructional designers. However, as the word 'spread' about the study we were contacted by, and accepted, instructional designers from four-year university colleges and non-doctoral institutions. Participants were accepted if 'instructional design' was specified in their job descriptions and if instructional design activities comprised at least half of their designated responsibilities For this particular study we chose not to include designers from the private sector or from other public institutions such as government departments, or from not-for profit organisations or the military, as we were most interested in the potential for instructional design to transform the perspectives of instructional faculty and the implications for cultural change within tertiary educational institutions.

\section{Method}

Participation was elicited through a range of strategies including personal email invitations, advertisements on lists and in institutional communications platforms, personal contacts at professional meetings and through collaborative projects, membership lists from professional associations, contacts through delegate lists from conferences, and visits to graduate classes. We also employed snowball sampling where existing participants recommended additional participants from among their colleagues (c.f. Salganic \& Heckathorn, 2004). Sources of data include research conversations with individual instructional designers, email exchanges, written observations of project design meetings, group meetings and/or 'story circles.' For example, a network of instructional designers in Saskatchewan, Canada received funding for three years to bring together instructional designers in provincial institutions, and teachers from the province's cyberschool, at an annual two-day design workshop featuring plenary sessions, concurrent seminars and interactive activities. In 2004 Campbell provided a plenary session to this group introducing the study and invited participants to attend a concurrent session to 'share stories of practice' in a facilitated format. The invitation attracted about twenty participants, of which four spoke about their experiences as instructional designers (Schwier, Campbell, \& Kenny, 2004a). Earlier that year we presented the study at another professional meeting that we had advertised to confirmed conference delegates by email, issuing at the same time an invitation to share stories of practice after the afternoon's scheduled poster sessions. We attracted four participants who later elaborated their stories in several email exchanges (Campbell, Schwier, \& Kenny, 2004). These stories were triangulated with the other data sets that, taken all together, paint a rich portrait of instructional designers’ daily encounters, activities, and tensions.

Study participants brought a range of educational and professional credentials and experiences to their roles: for example, one participant had a doctorate in theology and a decade of related teaching experience at a theological college, but returned to university to obtain a graduate degree in adult learning. Another had an undergraduate degree in science and a technical certification as a videographer, and was currently studying, at night, for a diploma in distance education. A third had obtained an undergraduate teaching degree as a mature student, and had taught business courses for several years at a college before returning to university for a graduate degree in 
educational technology. As we were interested in whom Canada's instructional designers are, we did not restrict the sample to those with graduate degrees in educational technology, nor to those with prior formal educational backgrounds; these biographies are typical of the twenty instructional designers involved in this study.

The main study is constructed as a narrative inquiry conducted mainly through the development of collaborative conversations. The 'opening gambits' — designed to encourage designers to explore what they know, how they know it, and how this influences their actions in the particular sociocultural contexts in higher education - refer to their lives as learners and their memberships in social and professional communities, their career choices, their core values about the purposes of education and of design, and their design practices. We invited participants to recall practice dilemmas and to describe projects of which they were particularly proud. For example, in the following excerpt with Anna, a practicing designer and a doctoral student in an educational technology program, one of the authors began a conversation by sharing her own memories of starting school, then asked her to describe:

... how you see yourself as a learner and what your values are in terms of learning, and how that influenced a lot of the choices that you made ... the last time we talked about your career trajectory and ... things that influenced ... your personal context (and) ... your choices in your career ... Then the third time around I will ask you more about ... social influences ...

Anna replied:

I've never left school ... I would say I am addicted to learning ... I've got a list of things still to learn. So it's a way of life, for sure.

Asked whether she had 'an addiction to the educational environment or an addiction to learning or are the two the same to you?', she responded:

I think it is spiritually driven because the more you learn there is always incidental learning that comes, not just the subject of learning but everything around it ... I think that is the addiction because the levels of awareness just keep on increasing and increasing ... it is more of a spiritual drive. It's more fulfilling now ... And it is just not formal learning, of course, it's informal learning because every time you take a trip it becomes a learning experience ...

Anna continued to frame herself as a learner.

Learning is also sort of the interaction of that knowledge that you've gained with your life activities. So ... that describes me as a learner ... at one level ... I am learning more for the affective side of learning ... it kind of creates a level of wisdom inside of you so maybe things get tapped away but it really more than anything enhances your intuition. Maybe that is why I am in instructional design, because there is always a problem to solve and to bring structure to and to find a solution ...

Probing for the link between her experience of learning and her understanding of the learning experience, and her decision to become an instructional designer, the researcher asked, 'So you saw design as ... a problem-based profession ... about solving the real world problems?' And Anna made the connection between her 'addiction to learning', her career choice, and her belief about how to practise design:

But also there is a big side ... where you are constantly being plunged into new environments and learning and walking away with this huge void filled up in your head that you didn't have before ... and it kind of feeds the soul. 
In this case, Anna and the researcher talked four times, each conversation unfolding over several hours. While the researcher had an informal protocol to begin with, Anna soon began to lead the inquiry in unexpected directions as she sorted through her experiences and thoughts, many of which were catalysts for shared stories between her and her 'conversation partner.' Another designer talked to a researcher twice for one hour each, providing short directed responses to probes. This data set more resembled a semi-structured interview, and initially was disappointing. Yet a third embraced the experience as 'a journey' and engaged in five conversations ranging from one hour to over two hours each. One participant was able to talk to us only once, but the conversation had such depth that once was 'almost' enough. As they unfolded these conversations reflected the emerging nature of conversation-as-design — the relationship between the designer and researcher often determined the texture and depth of each story.

\section{The Rationale}

In this paper we intend to make the case that narrative inquiry and the storying of experience are socially and contextually situated interpretive practices. We start from personal stories as 'personal knowledge has a practical function, not in a technical sense, or as an instrument for previously determined outcomes, but leading back to Aristotle, as a source for deliberation, intuitive decisions, daily action and moral wisdom' (Conle, 2000, p. 51). That is, the study and deep understanding of instructional design practice is most accessible to us in the forms in which designers actually do design: through a series of socially-referenced, scaffolded conversations that reveal how and why design is done and how we can use that understanding to prepare and support designers to practice in the most agentic, authentic, and profound ways. For the instructional designers involved in this study, and for us as doers, teachers and researchers of instructional design, co-constructing stories of practice requires a personal critical, reflective engagement with the potential to change or transform our practice. Thus, the methodological approach for the study mirrors a social constructivist framework for instructional design practice, which is one of social interaction and construction of meaning through conversation.

The conversations we included in this paper were selected from the pool of data because these participants told stories that very directly reflect the practice dimension of conversation. We chose these conversations because they are particularly focused on and illustrate the idea of the design conversation. That is, we are not concerned as much with generalising findings as we are with representing the plausible, the authentic, and the compelling in accounts that are both believable and invitational.

\section{Data Analysis}

Two researchers independently coded each transcript of the conversations using Atlas $\mathrm{Ti}^{\mathrm{TM}}$ software; the third completed a broader thematic analysis. That is, two researchers used a micro coding approach while one examined the transcripts with a wider lens: as themes emerged, they were negotiated with the research team and shared with the participants, and used to construct networks of meaning. For example, a segment might be coded as 'series of tasks in ID', a second might be coded 'learning to use Microsoft Project' and a third coded as 'trying to get content on time'. A broader theme of 'project management' is then identified for the transcript. However, the third researcher could interpret the transcript, along with half a dozen stories from other designers in the study, from an identity frame: 'Who am I as a designer? Just a project manager who checks off tasks? What is my level of authority in this process?' This reflexive process is intended to further engage participants in identifying emerging personal and community issues related to instructional design by bringing the personal and community problems of practice into self-awareness, leading to social action. In this way, narrative inquiry involves the 'politics of identity construction and ongoing identity maintenance', where the lived experiences of instructional designers can 'be used as the sites wherein and whereby we interrogate the social world theoretically and critically’ (Goodson, 1995, p. 4). 


\section{Conversation as Inquiry: An Alternate Frame}

Instructional design as a field is now five decades old. It is generally accepted that ID practice was originally based on the behaviorist learning theories of Skinner and Thorndike, among others (Saettler, 1990), and that instructional design was based on the empiric assumption that behavior is predictable; that educational design can occur in isolation from the contexts in which learning will take place (Koper, 2000, p. 8). Conventional literature in instructional design concentrates very intensively on process: how instructional design is carried out, what strategies and approaches work in various contexts, and how designers should systematically practice their craft (c.f. Dick, Carey, \& Carey, 2005; Morrison, Ross, \& Kemp, 2004; Seels \& Glasgow, 1998; Shambaugh \& Magliaro, 2005; Smith \& Ragan, 2005). These are supposedly value-free ways of shaping and representing knowledge based on the assumption that educational technologies and environments are neutral and democratic, that knowledge can be codified and presented in templates or blueprints that describe what knowledge is in a 'known world'.

Designers, programmers, and media developers emerging from this 'scientific' field have learned models that value objective, rational, instrumental, and empirical approaches (Garrison, 1993; Vrasidas, 2001). Bichelmeyer, Smith and Hessig (2004) asked ID practitioners what instructional design and technology meant to them, and while the most frequent response was that it was broad and diffuse, the second most frequent response was the ADDIE (Analyse, Design, Develop, Implement, Evaluate) model or systematic design of instruction. This may signal the possibility of developmental levels - perhaps younger or less experienced designers talk about tasks and technologies rather than larger implications of their work (Schwier, 2004). Recent research examining the actual practice of instructional designers suggests that designers do refer to conventional processes in instructional design, but practice varies significantly according to context (Cox, 2003; Cox \& Osguthorpe, 2003; Kenny, Zhang, Schwier, \& Campbell, 2004; Rowland, 1992; Visscher-Voerman \& Gustafson, 2004) and that key aspects of instructional design have been overlooked in conventional literature. Regarding the preparation of instructional designers, critical theorists have described the products and environments graduates produce and deliver as often prescriptive, restrictive, and reductionist, due in no small way to the culture they have acquired within their areas of study and the training that they have received. In our own community, Gibbons (2003) argues that we need to re-examine the assumptions and foundations of instructional design and align it more closely to other design sciences such as architecture and engineering, while we have called for instructional designers to frame their practice as moral action (Campbell, Schwier, \& Kenny, 2005).

If instructional design practice has until very recently reflected an objective, rational approach, so has research about instructional design. The search for a design science has emphasised one of four distinct paradigms: (1) the physical science or media view; (2) the communications/systems view; (3) the behavioral science-based view; and (4) the cognitive science perspective (Saettler, 1990). For example, the cognitive approach, emerging from the behavioral science approach, endeavored to understand a learner's internal cognitive processes, such as thinking, organising and remembering, and activating the appropriate learning strategies during the instructional process. This approach considered media attributes, learner strategy implementation, and task analysis (Saettler, 1990). But, in all these views the instructional designer's agency is restricted to systematically choosing and applying the design model likely to yield the most effective instruction. The design-science vision eliminates the messy process of problem solving where non-systematic human thoughts and emotions are involved; this is the grand narrative of instructional design that has underpinned its dominant cognitive science culture for many decades (c.f. Braden, 1996; Dick, 1996; Willis, 1998).

The cultural shift occurring over the past decade in education towards environments and approaches based on the ideas of social constructivism is beginning to frame design practice, in particular. In this worldview, learning is situated in rich contexts, and knowledge is constructed in communities of practice through social interactions. Common ground established between knower and learner must embrace interests and personal values, which requires a sharing at both the sociocultural and the cognitive levels (Ewing, Dowling, \& Coutts, 1998, p. 10). 
Social constructivists are interested in prior experience that is shared through conversation, negotiation, and construction of new knowledge products. In this view, an instructional designer's practice, to which self-reflection is critical, will reflect his or her values and belief structures, understandings, prior experiences, and construction of new knowledge through social interaction and negotiation. Johnsen and Taylor (1995) referred to this personal dimension of instructional design as 'human inventions that spring from human values and human designs. They are valuesaturated and operate in the social world ... (resonating) with the values of their human creators, who themselves are situated in a particular culture in a specific time and place' (p. 94). An alternative knowledge community with multiple knowledge structures, such as academia, expects members to negotiate meaning and co-construct knowledge in a social exchange.

Our view of instructional design practice sees knowledge embodied within individuals in a relationship of faculty clients/collaborators and instructional designers, who together interpret their experiences through personally and socially constructed visual and verbal forms, whether that be language, metaphors, pictures or demonstrations (Connelly \& Clandinin, 1990; Ellis \& Bochner, 2001). This approach also acknowledges the social representation perspective, which argues that practitioners construct their knowledge of the social world based on practical understanding obtained through experience and interaction. In both social constructivist and social representation approaches, the 'communicated character of thought and the role of social groups in the development and communication of social knowledge' (Walmsley, 2004, p. 5) emphasises the instructional designer as an actor in a social world.

We contend that much of the instructional technology research that has informed the development of design models has supported the delivery of an authoritative and relatively fixed knowledge base. If, as Hlynka and Belland (1991) suggested, and we concur, decisions made in the course of instructional development are often experiential, intuitive, aesthetic, and phenomenological, related instructional design research should reflect critical paradigms that 'provide a mode of inquiry which can provide insight and information which goes beyond the possibilities of scientific inquiry ... [into] the realm of art' (p. 9).

In this paper we make a case for narrative as a form of critical inquiry in instructional design practice. The case hinges on the role of language in representing a social system of values, ideas and practices that a community of practice shares as a 'commonsense understanding of the social world' (Walmsley, 2004, p. 3). This method asserts that meaning making is contextual and relational, in other words, the research situation is constantly evolving and the account of it, the research story, is formed in relationship. Both researcher and researched are implicated in the narrative, and from it both learn something about the phenomenon, and about themselves (Murphy \& O’Brien, 2006). The unstructured interview design, or collaborative conversation, thus captures the participants' constructions and interpretations of experience, their families and social cultures, their seminal personal and professional encounters, their moral and ethical beliefs and dilemmas, their development and understanding of their work as instructional designers and how their knowledge is embodied in their relational practice with faculty. The conversations made a space for the researchers' stories, and the relational creation and re-creation of the social reality of instructional design. In this representation of the process, we explore four main ideas as methodological issues: reflexivity, voice, strong objectivity, and power/authority.

\section{Reflexivity}

Designers we have included in this account describe their practice as story-based; they design by asking a faculty to tell stories about their teaching and reflect these stories back through the design. Telling a story requires reconstructing a plot, ordering the events to build to a climax, and characterising the actors and their motivations in a form that helps faculty make personal and instructional meaning from it. Storytelling is a reflexive project that recounts personal action and reflects learning for both faculty and designer. In a design conversation, both designer and faculty are critically aware of each other's role in the interaction that affects the telling and challenges the other's construction of the story. 
What emerges from this conversation is a socially transformative story of the design process. The narrative conversation is a fundamental activity of mind, involving an intentional reflective activity (Lyons \& Kubler LaBoskey, 2002). As we talk to the designers about these projects, the temporal distance requires a cognitive and emotional reconstruction of the experience. In its collaborative form the conversation becomes an opportunity for growth for both designer, who has new knowledge to reuse, and the researchers-as-designers, whose new appreciation for the design process is reflected in both refined methods/better questions and enhanced design practice.

\section{Voice}

As a conversation-based practice, instructional design is plurivocal, as is the research conversation. In the conversation, clients and designers and researchers share space and moral authority in the acts of listening, taking turns, attenuating: acting in each other's stories. The story is 'a statement of belief, of morality, it speaks about values' (Goodson, 1995, p. 12). The shared process of storytelling experience establishes complex interrelationships, is social and political and assumes equity - in the end no one owns the story, because neither the design nor the research story would exist without its telling and its hearing, and its resonance and dissonance with the listener's experiences (Gudmundsdottir, 1998). As researchers, we can interrogate design practice through active social participation in the conversation, because storying the design experience requires conscious knowledge and understanding of action (Lyons \& Kubler LaBoskey, 2002).

Accountability to the storyteller and the story becomes both an ethical and a methodological (interpretive) issue in this research. Even though we intend that the conversations be collaborative and equitable, the final account presents a problem of knowledge representation (Willinsky, 1989). In recounting the conversation we have co-opted the representation by selecting from the conversations what we need to make our case; the accountability obligation increases the more interpretive lens between the storytellers and us. For example, in a conversation there are silences, facial expressions, vocalisations; certain stories become unavailable. If we listen to the tape while interpreting we may be aware of these 'meaning units' but may choose not to include them. If we were not present during the conversation and are working with transcripts only, we might not realise that an extended silence occurred because the designer was struggling to gain control of his emotions. In one transcript, our transcriber inserted comments like 'laughs nervously' and 'sighs heavily', which was her interpretation of the emotional context of the conversation. Another transcriber did not insert any affective or descriptive markers in the transcripts. Listening to the tape from an earlier conversation, one researcher realised that she was talking more than the designer, an indication of unequal voice. However, another way to interpret this interaction is in its mutuality: the stories were so resonant that the conversation reflected deep connections in parallel finished thoughts and shared cultural memories.

\section{Strong Objectivity}

Instructional design is a social project, guided by the personal narratives of designers and faculty. Understanding the process is likewise a social project with moral and political undertones: moral in that the design conversation reflects values and beliefs that guide practice, and political in that practice at least implies the possibility for social action in the institution. As designer-researchers we are agents of change, because we can retell design stories in ways that may challenge the dominant research culture of instructional technology. Our shared experiences with designers, rather than our differences, draws us into this project because we have chosen issues close to our own hearts and we feel morally responsible to represent a social process much different from the impersonal, objective process represented and reinforced through more traditional modes of inquiry in instructional technology. These modes do not reflect design practice, let alone design epistemology. This, in essence, is why the research conversation, like the design conversation, is a moral rather than a technical act (Herda, 1999). 
Science's 'concern' for a reproducible product is reflected in its research methods. Consequently, alternative research frames have been held up to the 'quality measures' common to science's requirement for 'truth claims' — reliability, validity, generalisability; the rigor associated with objective design. But narrative inquiry, in which conversation is both design and data, is more critically concerned with ethical conduct, voice, reflexivity, and resonance. The researcher brings his or her 'cultural self' as a set of resources for the relational work of narrative. Utilising oneself as source and interpretive resource is critical to understanding how the research process is unfolding and how meaning is made in conversation. In other words, identifying the interviewer as a designer-researcher permits us to use the commonly understood language of design. A shared language enables us to 'create and acknowledge meaning as we engage in discourse and fulfill social obligations ... [that] are characterized as moral activities' (Herda, 1999, p. 24). We become part of the past and the future as 'temporal and social, cultural horizons are set and reset' (Connelly \& Clandinin, 1990, p. 5) through the conversation; our stories are merged and emerge as scripts for further practice or action. The quality measure in this is the moral obligation we share as designer-researchers with designers to 'tell it the way we now understand it', rather than as 'the way it was'. This strong objectivity requires that we investigate rather than deny our relationship with our conversation partners (Harding, 1993).

Because in understanding human action there is just no way to neutralise the social nature of interpretation - an ongoing process of active listening that allows us to engage during the conversation - being strongly subjective requires us to explicitly, consciously and critically examine and respond to the interpersonal dynamics. The relationship between us pervades every aspect of the process, determining the quality and quantity of the information gathered (Cole, 1991); as a component of trust, the collaborative sharing of personal experience enhances a reciprocal relationship. For example, rather than adopting and trying to maintain an objective distance during conversations with the designers in my department, I respond with, 'I know exactly what you mean! That happened to me too! I didn't resolve the problem very well, what did you do that I can learn from?'

\section{Power and Authority}

Empowerment is a goal of conversation as inquiry. The goal is political because we have a different purpose from historical and traditional forms of educational technology research to define 'evidence-based' instructional design models and control the ways that designers are supposed to practice. Because they encourage us to see the design world and understand our own design practice in new and different ways, these stories become counter-narratives that compete with the existing grand narratives of an instructional design science (Elbaz-Luwisch, 1997; Kanno, 1997; McEwan, 1997).

In this study we have heard about the power of the relationships that designers build with each other and with their clients. These relationships can reflect their concern for vulnerable faculty dealing with the cultural expectations of their institutions and disciplines (Schön, 1987), and at the same time with the personal pain of class membership in that same hierarchical culture. We have heard stories framed by the struggle for identity and credibility resonate with our own experiences as designers, and as qualitative researchers in this field (Schwier, Campbell, \& Kenny, 2004c). However, it came as a surprise that our designers sensed the same inequity in power and authority with us; at least one of us was seen in a supervisory role, and so another interviewer was brought in for later conversations.

This raises questions about power and authority within a research relationship defined as 'collegial' by the researcher, who is also a designer, and the participant, who feels uneasy about fully disclosing conflicts, mistakes; times of doubt in her practice. This sort of dilemma highlights the differences in epistemology and purpose between objective, 'patriarchal' (traditional experimental design) and emancipatory (narrative) forms of research. Shotter and Logan (1988) suggest that the former leads to a 'decontexted kind of theoretical knowledge ... expressed in a hierarchically arranged, closed system of binary oppositions ... concerned with ... a unity of 
vision and thought ... everything in its proper place and all conflict eradicated, once and for all' (p. 75). Emancipatory forms contextualised by relationship, on the other hand, make space for a 'plurality of otherwise conflicting voices' (p. 75).

Earlier we identified empowerment as a goal of this research. We have determined, to not much surprise, that designers struggle with identity and agency in a practice and research culture that privileges individual, monological knowledge held in an authoritative closed hierarchy. The current project positions us as members of the design and the research communities with a particular vision: as designer-researchers trying to influence the power dynamics in educational technology research we can democratise the structures that specify the sphere of the designers' professional action by clearing space for their authentic stories. Practice is contingent on social context, and what we learn from these conversations about practice is likewise of practical and contingent use in professional development, graduate study, and research contexts. Herda (1999) captures the idea of designer-researcher agency when she responds to her own question, 'How do we change our actions as researchers within the broader professional community so that our findings may take on a significance in our own lives and in the lives of our participants?' (p. 91) in two ways: (1) by grounding our notion of action in moral decisions rather than in behaviorism, and (2) by changing our idea and understanding of professional identity.

\section{Instructional Design as Conversation}

In the second part of this paper we explore critical questions about the conversation-based, social practice world of the instructional designer through the four integrating ideas of reflexivity, voice, strong objectivity and authority. These ideas are articulated through the pseudonymous voices of three designers, Steve, Yan and Maria. We invite the reader to consider how his/her design practice might also reflect the development of these ideas in the process of constructing design with their clients.

\section{Steve and Wilhelm: Conceptual Constraints and Reciprocity}

Steve came to the university as a graduate intern from a well-regarded graduate program in another region. The program was significantly project-based; the university was ideally situated to attract clients from the corporate sector. Graduate students learned the 'evidence-based' models (for example, ADDIE) and became skilled at experimental research design. Steve was attracted to the internship placement because the development centre had just been established as a centrally supported unit working with faculties in a professional development model. He was pleased to be able to contribute to 'building processes internally ... so a lot of the design work was actually experiential'. Rather than adopt any one specified instructional design model (as he had been trained to do in his graduate program) the evolutionary approach at the centre encouraged him to work intensively with a faculty based on their personal connection with each other. His design approach involved a long phase of informal conversations followed by another phase of formal, team-oriented design meetings. Steve felt that 'change', that is, faculty learning, happened in the first phase, where in the second phase design decisions were consolidated to be implemented by a more technical/production group.

Steve talked about one project in particular that in retrospect had the most influence on his growth as a designer. The faculty client, Wilhelm, an internationally renowned teacher/philosopher, was initially very skeptical about the support that a virtual environment could provide to his work in hermeneutics. A pragmatist, Steve had his own doubts about the nature of hermeneutic inquiry, admitting that he is 'more empirically minded so a lot of what he would talk about I couldn't buy.' Conceptual constraints helped the design conversation evolve as each struggled to understand the knowledge base and values of the other.

As Wilhelm described his instructional approach, Steve visualised 'lessons that would just sort of unfold ... they are not designed, they are not planned, they unfold and that is part of that whole 
philosophy ... allowing that to happen.' Accepting that this was a viable model challenged Steve's beliefs about a designed learning environment. Wilhelm's teaching was conversationbased, reflecting his deep curiosity about how individuals live in and understand their world. Steve remembers that "there was always this conversation about "Well, how do you interact with the students?" and he would describe things that he did in the classroom.' At some point, Steve understood enough about Wilhelm's learning goals, embedded in his experiences of and beliefs about living actively in the social world, and his responsibility as a teacher to represent that kind of relationship with life phenomena.
We were also talking about how we could create these ... experiences for students to go through, still have some sort of communication with one another as they go through the experience but really to allow it so it wouldn't need to be managed (by Wilhelm) ... we came up with a number of activities including things where students would ... be given pictures and then they would quickly ... respond to the pictures with their feelings or with their thoughts or whatever the picture evoked ... they would go through a number of these and they would be randomly pulled out of the database and then they would go through them again but with other people's comments attached and then they would make comments and then (Wilhelm) would use these ... to talk about ... different things about the experience ...

The resulting design, an interactive concept map, is one outcome of a process in which Steve struggled to understand a way of looking at the world so that he could help Wilhelm faithfully represent online the dialogic nature of phenomenology. But while at times the design conversation was ‘over my head' there was also a ‘deeply cultural reason' for liking and personally committing to Wilhelm,

... a shared cultural heritage ... my background is German ... (his) accent always reminds me of members of my family ... and one of my favorite high school teachers was actually a student of (his). He did his Masters with Wilhelm. I remember ... this teacher talked about Wilhelm ... and then his son was my best friend in high school ... (Wilhelm) always reminds me of that teacher ... less because Wilhelm is like him, more ... because my teacher was like Wilhelm ... There's this certain way of looking at things.

We picked up on the notion that a shared cultural heritage opened up a space for Steve and Wilhelm to work in harmony:

I am just sort of trying to think about that from a cultural point of view. That is a way of looking at the world that was really ... really resonant for you, right? So here's Wilhelm ... there are lots of ways that you connect with him and yet he brings in something to work on, a project of his, that is in many ways really kind of dissonant for you. (researcher)

Steve responded that not-knowing actually allowed him to ask authentic questions that encouraged Wilhelm to interrogate his own assumptions, and ... 'start breaking things down further in further pieces and examining assumptions and help (Steve) to help them understand where the learning problems are gonna occur'.

We see that through this exchange, Steve reveals that the agency relationship is not directional; it is reciprocal. Both participants influence the processes of the other, and both change. Certainly the amount of reciprocity between a designer and client is defined by the relationship and the institutional context within which their relationship operates. For example, an institution that emphasises a hierarchical relationship between faculty and designers introduces power and authority to the conversations, and this would likely intrude on the reciprocity of the relationship. 
And when there is true reciprocity, it can introduce dissonance to the conversations, and the resolution of that dissonance can result in designs that are marked by nuance and depth.

The relationship is moral because it leads to positive action. The design does not even have to come to fruition, in fact it often doesn't. It's the process, the conversation, and the relationship that is important. Steve sees his own moral authority in his influence on faculties' changed perspectives.

Well that, those are beauties, because they were more, because they were people that would come back afterwards and say, "I'm teaching differently now”. Because of our interaction I'm teaching differently and that would be like an epiphany, right? Even Dr. Stone ... (whose) project never got off the ground, he would come back and we would talk about other things ... we would talk about the problems he was having, we would talk about ways that he could address them, and afterwards saying, you know, "I’m changing the way that I'm looking at these instructional problems for my classroom”.

We think that instructional designers in universities have been marginalised by the suspicion of a technology of instruction, a view whose genesis is in the quest for a science of instruction that is impersonal, rational, and free of conflict, contradictions, beliefs, emotions, and personal values. Steve's story of the 'Wilhlem project' stands clearly in opposition to the grand narrative of an objective science.

\section{Yan and Design as Activism}

Yan is typical of many in this study who 'cut their design teeth' in settings other than universities, and before obtaining formal graduate education in the field. We have observed that these designers tend to bring both a pragmatic and a political sensibility to their practice at universities. For example, Yan and Maria, the designers in the next two stories, chose to pursue the study of instructional design because they saw a graduate degree as an important credential for establishing credibility in a culture defined by domain expertise, as well as providing opportunities for professional growth and advancement in the field. At the same time, each understood the practice of instructional design as a way to embody their goals of accessibility and inclusion.

Yan refers to her background as lower middle-class, giving her an interpretive lens in the 80s and 90 s as she worked in various community service settings with 'the disenfranchised'.

It seems to me that ... there's kind of a political landscape that has allowed ... especially people who are disenfranchised or just disadvantaged in some way, to be pushed even further down in terms of their own ... opportunities. That has been ... a consciousness that has evolved for me in the past twenty years.

Aware of the lack of social engagement of some faculties, Yan talks about teaching and design as political acts whose purpose is to improve the kinds of learning opportunities that will lead to social justice. Soon after obtaining an undergraduate education degree she took a full-time position as an ESL instructor in a community college with a large student population of political refugees. Her colleagues 'had a very radical orientation to education, were quite active in a number of political movements':

awakening my awareness to larger issues because when you talk about teaching in that context, you're not just talking about content; you're talking about a wider role, like what are issues of social justice? So this idea of the content is important, but it's not the only thing ... and it's quite interesting for me to come (to this university) and work with professors sometimes who 
are very knowledgeable in their area, but they're so focused on that one area, it's hard for them to convey to their students what the significance of that content is within the wider context of the world. So that's an interesting situation for me ... not as a result of my formal education; it's more my informal education through working with people who were very, very committed educators ... a very inspiring bunch ... who really walked the talk of what they believed ... who were very much into people like Freire ...

As a result of this powerful socialisation to critical frameworks for education, Yan decided to pursue an 'interdisciplinary (Masters) between adult ed and technology' with the hope that using learning technologies would broaden access for the groups to whom she had been committed for two decades. Instead, she found a 'micro-focus' on technical skills. When we talked about ways to have the sociopolitical impact engendered by a more critical focus for instructional design she pointed to writing for the professional community — she was working on a chapter for a book on technological and information literacy. Interested in equality (as) 'a value that I bring to the table' and seeing 'nothing in there in terms of marginalized groups' she decided to 'shoot this chapter in.'

Yan's practice as a designer is framed by a moral purpose, in some ways a purpose she disguises when working with faculty with more instrumental goals. She describes one project in the health sciences in which, by having a series of conversations about her own experiences as a teacher, she convinced an initially skeptical client to develop case studies framed by a relevant social issue.

A family came back in a couple of different case studies and I tried to make them lower middle class in terms of how they talked ... one of the characters decided to become a vegetarian and she announced at the dinner table that she was an ovo-lacto-vegetarian and her father said, "What the hell is that?" And the ... instructor said, "That's really funny. That's exactly what my father would have said". ... I kind of wanted to set the stage - here's a family that is struggling financially ... the father loses a job. The daughter is in university ... and in the very last story the daughter is visiting the food bank at the student union. So we have a whole case study in terms of student hunger. We wanted to make the case studies relevant to student life and the fact that there are probably people on campus who don't have enough money for a balanced diet.

Yan immediately identified this project as one where she felt her own values were aligned with the goals of the faculty.

I have to say I really like working with the nutrition people ... their practice is very applied ... because there's a social science element to it ... so they're trying to include things in their introductory class - like aboriginal health ... social issues are part of that mixture ... The people who work there reflect that. They're very straightforward and pragmatic.

Yet, while Yan knows she has some authority to work in moral, relational ways, when her clients focus on content outside of the context of significant cultural political issues, she wonders whether she has any impact on the socially detached culture of the university. She looks back at her early career 'dealing with people who saw half their family get killed, and now they're in a new country, and they have to learn the language and how do you get a job'. She has identified other ways to measure success that reflect the global social conscience that embodies her personal and professional values: 'So I have to measure success in a different way ... that the instructor has acknowledged that there are more people in the class other than the keeners ... And I really feel the few things ... like the teachable moments ... have been very worthwhile. So I hope (I have) some impact in other ways'. 


\section{Maria and Intellectual Wrestling}

Maria came to instructional design through teaching and personal crisis in her family — she tells a story of serendipity that brought her to a design unit in a university. Maria feels that her instructional design career reflects her life, as part of being 'constantly in process.' She credits relationships with colleagues and faculties with being 'extremely instrumental' in helping her define her goals 'flow(ing) towards what I think now is more authentically what I need to be doing.' Maria's design approach is referenced by her memories of learning, and of teaching in a college, seeing explicit connections between her experiences, values and practice.

Maria told the story of a development project for a theology course for which she very deliberately lobbied her supervisor; she had been in touch with the Dean of the Faculty in which the course was based and was challenged by the nature of the design problem. The instructor was untenured, a new hire working on his dissertation in philosophy. Maria had met him and connected on a deep level with him as she respected that 'religion ... really gets to the heart of who a person is and how they interpret the world' and she was interested in exploring how his spiritual lens would frame the design process. She found that he did not have a lot of experience in the classroom and that:

his own experience in the teaching process had been very lecture-oriented and his vocation as a priest is very intellectually-oriented ... in the first few meetings he came across as ... having very strong opinions about what he thought could and couldn't be done and was quite skeptical about whether or not a course of this nature could be taught.

In fact, he initially characterised the Internet as a ‘tool of war and social aggression'.

Committed to his professional growth, Maria intended to 'set up some cognitive dissonance' through a series of conversations. They met many times, informally, to talk about the meaning of worship and the goal of religion in the schools. She attended a Mass. She describes her 'own personal feelings' about course development and her role as a facilitator, respecting the relationship and at the same time requiring 'a sort of intellectual wrestling ... posing challenging questions about what it is they are doing, why they are doing it; why they think that might work ... perhaps creating enough discomfort about that, [so] that change can happen ...'.

Although the instructor was initially resistant to the idea of technology, she 'never felt resistance from him personally'. She noted that 'after several months ... he was starting to integrate things that we had talked about even in his face-to-face version of his class and that he was thinking about and wrestling with the way he was teaching, what that meant ...'. Maria recounted the months of deep conversations about the experience of worship and the place and value of that in schools.

Maria resists educational technology's sacred belief in the optimal, reproducible, science of course design. If a client's 'absolute insistence' on a particular approach is ill advised, she will still try to 'somehow honor that piece and come up with creative ways of making it happen that will be useful to learning'. Her ethic of care for the person involved in the process 'comes back to my original feeling that this course has to be a reflection of the person that is teaching and has to be part of their personality, they have to buy into it.' Maria is purposeful in a design conversation that values a more reciprocal, relational process in which both participants experience profound growth. In this way she reflects back a passion through a sort of affective resonance:

what he said was that what he found in me was a great conversationalist and that we were able to talk through lots of things ... he actually said he always felt very empowered to do this and that ... for both of us the discussions were always enjoyable, were always an exchange ... You have to understand ... whatever the content (he) was trying to address we would end up in conversation about that ... he was very forthcoming about how he felt 
about that ... there was a ... kind of mutual interest in terms of him being interested in what I was able to offer as an instructional designer and my interest in his content.

During the research conversation with Maria, we were invited to the course launch in the Faculty, which was framed by a ceremony of worship and celebration. The instructor talked very movingly about his transformed teaching practices and his acceptance of the Internet as 'an enabler of peace and community'.

\section{Final Thoughts}

During the time that this paper was under development, the lead author's Faculty was engaged in a renewal process during which we interviewed ten individuals for several tenure-stream positions. One candidate was asked to describe a course that he had taught that he felt was particularly successful. He recounted his struggles over two different terms with an undergraduate communications course that was not receiving positive student evaluations. 'You know', he said, 'the problem was I just couldn't find the narrative thread that would pull it all together.' On the third iteration a designer/colleague got him talking about sociopolitical dimensions of his work, and that spurred a re-design to a case-based model for the course. He concluded that the conversation had helped him see 'that there was a narrative to be explored' and at that point the 'course came together' for the students and him.

At the beginning of this paper we framed instructional design as an active practice based on community, practical reasoning, personal perspective, and semantic innovation involving memory and leading to action. Exploiting the metaphor of instructional design as conversation has implications for both personal and social action. Understanding this process through conversation has implications for both professional and methodological change in our field, because the narrative conversation has moral, emotional, aesthetic and intellectual dimensions, and design is all of these.

More than a decade ago, Murphy and Taylor (1993) described their experiences, as faculty members, in a course development project. Their aim 'in telling the tale is to show that the development of learning materials does not take place according to the kinds of models that one typically comes across in most instructional design textbooks'. Arguing that such models 'restrict rather than foster the kinds of creative processes' necessary for effective design, they referred to the emotional and intellectual complexity of design by describing the process of 'confusion, conflict, ambiguity, and uncertainty' (p. 45).

The reality is that this 'messiness' (c.f. Schön, 1987) should not be seen as a problem to be overcome, but as a stimulating and creative environment in which relationships, rather than content, are at the center of the action. Connelly and Clandinin (1990) refer to the central task of narrative as representing 'people (that) are both living their stories in an ongoing and experiential text and telling their stories in words as they reflect upon life and explain themselves to others.' For us this is both the central task of instructional design and the power of narrative to reflect that. Narrative inquiry provides a space for designers to talk about their moral and ethical choices for design in an ill-structured world, choices made in relationship with faculty. Narrative inquiry also helps us understand 'the conventions that constrain which stories we can tell and how we can tell them, and to show how people can and do resist the forms of social control that marginalise or silence counternarratives, stories that deviate from or transgress the canonical ones' of instructional design practice and research (Ellis \& Bochner, 2001, p. 744). We believe that our practice, teaching and research in instructional design have not been critical enough of its foundational design-as-ADDIE, or design-as-science approach. Legitimating conversation as design and as inquiry has the potential to challenge the sacred stories of design. 
The stories we've included here demonstrate the kinds of things we can learn when we use conversation as a lens into our practice. An instructional design process in which faculty and designer work toward the 'imagined future' of the designed learning environment is a 'matter of growth' that 'involves retelling stories and attempts at reliving stories' (p. 4). Elsewhere we have suggested ways in which this model could be visualised in graduate programs in instructional technology, for example, by involving beginning designers in structured 'identity work' (Schwier, Campbell, \& Kenny, 2006).

Narrative implies relationships with moral dimensions - trust, reciprocity, reflexivity, plurivocality - that leads to critical reflection and has profound implications for practice and research. We found that instructional designers in higher education workplaces use narrative to assist faculty clients tell the instructional story; they have thousands of stories to share. And we learned that stories are at the centre of conversations that transform all of the participants in design projects. As researchers, we found that narrative is not just a powerful tool for learning about the multidimensional relationships that exist in every project, but that the stories of instructional designers and clients are inseparable from the directions and outcomes of projects. If instructional designers and their clients want to be successful, then stories are key to discovering the meaning that the players attach to their participation. All we have to do is ask, and develop a mindset that values what we hear.

\section{References}

Bichelmeyer, B., Smith, K., \& Hessig, J. (2004, October). Graduate students’ perceptions of the field of IDT. Paper presented at the annual conference of the Association for Educational Communications and Technology, Chicago, IL.

Braden, R. A. (1996, March-April). The case for linear instructional design and development: A commentary on models, challenges and myths. Educational Technology, 36(2), 5-23.

Campbell, K. (2004). Effective writing for e-learning environments (and other online spaces). Instructional Design Conference, Campus Saskatchewan, University of Saskatchewan, Saskatoon, SK.

Campbell, K., Gibson, S., \& Gramlich, C. (2005). On conversation and design. Journal of Technology and Pedagogy in Education, 14(1), 9-24.

Campbell, K., Schwier, R .A., \& Kenny, R. F. (2004, June). Supporting instructional designers: Sharing our stories and enhancing our practice. Paper presented at the annual meeting of the Canadian Association for University Continuing Education, Niagara-on-the-lake, ON.

Campbell, K., Schwier, R. A., \& Kenny, R. F. (2005). Agency of the instructional designer: Moral coherence and transformative social practice. Australasian Journal of Educational Technology, 21(2), 242-262.

Cole, A. (1991, March). Interviewing for the life history: A process of ongoing negotiation. Paper presented at the annual meeting of the American Educational Research Association, Chicago, IL.

Conle, C. (2000). Narrative inquiry: Research tool and medium for professional development. European Journal of Teacher Education, 23(1), 49-63.

Connelly, F. M., \& Clandinin, D. J. (1990). Stories of experience and narrative inquiry. Educational Researcher, 19(5), 2-14.

Cox, S. (2003). Practices and academic preparation of instructional designers. Unpublished master's thesis, Brigham Young University, Provo, UT.

Cox, S. \& Osguthorpe, R. T. (2003, May/June). How do instructional design professionals spend their time? TechTrends, 47(3), 29, 45-47.

Dick, W. (1996). The Dick and Carey model: Will it survive the decade? Educational Technology Research and Development, 44(3), 55-63.

Dick, W., Carey, L., \& Carey, J. O. (2005). The systematic design of instruction (6th ed.). New York: Allyn and Bacon.

Ellis, C., \& Bochner, A. P. (2001). Autoethnography, personal narrative, reflexivity: Researcher as subject. In N. K. Denzin, \& Y. S. Lincoln (Eds.), Handbook of qualitative research (2nd ed., pp. 733-768). New York: Sage Publications. 
Elbaz-Luwisch, F. (1997). Narrative research: Political issues and implications. Teaching and Teacher Education, 13(1), 75-83.

Ewing, J. M., Dowling, J. D., \& Coutts, N. (1998). Learning using the world wide web: A collaborative learning event. Journal of Educational Multimedia and Hypermedia, 8(1), 3-22.

Garrison, D. R. (1993). A cognitivist constructivist view of distance education: An analysis of teaching-learning assumptions. Distance Education, 14(2), 199-211.

Gibbons, A. S. (2003, September/October). What and how do designers design: A theory of design structure. TechTrends, 47(5), 22-27.

Glaser, R. (1991). The maturing of the relationship between the science of learning and cognition and educational practice. Learning and Instruction, 1(2), 129-144.

Goodson, I. (1995, April). Storying the self: Life politics and the study of the teacher's life and work. Paper presented at the annual meeting of the American Educational Research Association, San Francisco.

Gudmundsdottir, S. (1998, February). How to turn interpretive research into a narrative? Invited lecture at Oulu University, Finland. Retrieved July 14, 2003, from http://www.sv.ntnu.no/ped/ sigrun/publikasjoner/narroulu.html

Harding, S. (1993). Rethinking standpoint epistemology: What is "strong objectivity”? In L. Alcoff \& E. Potter (Eds.), Feminist epistemologies (pp. 49-82). New York: Routledge.

Herda, E. A. (1999). Research conversations and narrative: A critical hermeneutic orientation in participatory inquiry. London: Praeger.

Hlynka, D., \& Belland, J. C. (1991). Paradigms regained: The uses of illuminative, semiotic and post-modern criticism as modes of inquiry in educational technology. Englewood Cliffs, NJ: Educational Technology Publications.

Johnsen, J. B., \& Taylor, W. D. (1995). Instructional technology and unforeseen value conflicts: Toward a critique. In G. J. Anglin (Ed.), Instructional technology: Past, present, and future (pp. 94-99). Englewood, CO: Libraries Unlimited.

Jonassen, D., Dyer, D., Peters, K., Robinson, T., Harvey, D., King, M., et al. (1997). Cognitive flexibility hypertexts on the web: Engaging learners in making meaning. In B. H. Khan (Ed.), Web-based instruction (pp. 119-133). Englewood Cliffs, NJ: Educational Technology Publications.

Kanno, Y. (1997, March). Researcher-participant relationship in narrative inquiry. Paper presented at the annual meeting of the American Educational Research Association, Chicago, IL.

Kenny, R. F., Zhang, Z., Schwier, R. A., \& Campbell, K. (2004). A review of what instructional designers do: Questions answered and questions not asked. Canadian Journal of Learning and Technology, 31(1), 9-16.

Koper, R. (2000). From change to renewal: Educational technology foundations to electronic learning environments. Inaugural address of the Educational Technology Expertise Center, Open University of the Netherlands.

Lyons, N., \& LaBoskey, V. K. (2002). Why narrative inquiry or exemplars for a scholarship of teaching? In N. Lyons \& V. K. LaBoskey (Eds.), Narrative inquiry in practice: Advancing the knowledge of teaching (pp. 11-27). New York: Teachers College Press.

McEwan, H. (1997). The functions of narrative and research on teaching. Teaching and Teacher Education, 13(1), 85-92.

Morrison, G. R., Ross, S. M., \& Kemp, J. E. (2004). Designing effective instruction. Hoboken, NJ: John Wiley \& Sons.

Murphy, D., \& Taylor, G. (1993). A tale from the mud. In M. S. Parer (Ed.), Developing open courses (pp. 55-76). Centre for Distance Learning, Monash University Gippsland Campus, Churchill, Vic., Australia.

Murphy, S. A., \& O’Brien, A. (2006). “Listening above the din”: The potential of language in organizational research. International Journal of Qualitative Methods, 5(2), Article 10. Retrieved August 22, 2006, from http://www.ualberta.ca/ iiqm/backissues/5_2/pdf/ murphy.pdf

Rogoff, B. (1990). Apprenticeship in thinking. New York: Oxford University Press.

Rowland, G. (1992). What do instructional designers actually do? An initial investigation of expert practice. Performance Improvement Quarterly, 5(2), 65-86. 
Saettler, P. (1990). The evolution of American educational technology. Englewood, CO: Libraries Unlimited.

Salganik, M. J., \& Heckathorn, D. D. (2004). Sampling and estimation in hidden populations using respondent-driven sampling. Sociological Methodology, 34, 193-239.

Schön, D. (1987). Educating the reflective practitioner: Toward a new design for teaching and learning in the professions. San Francisco: Jossey Bass.

Schwier, R. (2004, October). A grand purpose for instructional design. Paper presented at the annual conference of the Association for Educational Communications and Technology, Chicago, IL. Retrieved June 11, 2005, from http://www.indiana.edu/ idt/shortpapers/ documents/IDTf_Schwier.pdf

Schwier, R. A., Campbell, K., \& Kenny, R. F. (2004a, November). Conversation with instructional designers about social change agency. Instructional Design Conference, Saskatoon, SK.

Schwier, R. A., Campbell, K., \& Kenny, R. F. (2004b, June). Instructional designers in search of identity and community. Poster presented at the annual meeting of the Canadian Association for University Continuing Education, Niagara-on-the-lake, ON.

Schwier, R. A., Campbell, K., \& Kenny, R. F. (2004c). Instructional designers’ observations about identity, communities of practice and change agency. Australasian Journal of Educational Technology, 20(1), 69-100.

Schwier, R. A., Campbell, K., \& Kenny, R. F. (2006, April). Transforming higher education: Towards an agentic model of instructional design. Paper presented at the annual meeting of the American Educational Research Association, San Francisco.

Seels, B., \& Glasgow, Z. (1998). Making instructional design decisions (2nd ed.). Upper Saddle River, NJ: Merrill Prentice Hall.

Shambaugh, N., \& Magliaro, S. G. (2005). Instructional design: A systematic approach for reflective practice. Boston: Allyn \& Bacon.

Shotter, J., \& Logan, J. (1988). The pervasiveness of patriarchy: On finding a different voice. In M. McCanney Gergen (Ed.), Feminist thought and the structure of knowledge (pp. 67-86). New York: New York University Press.

Smith, P. L. \& Ragan, T. J. (2005). Instructional design (3rd ed.). Hoboken, NJ: John Wiley \& Sons.

Visscher-Voerman, I., \& Gustafson, K. L. (2004). Paradigms in the theory and practice of education and training design. Educational Technology Research and Development, 52(2), 69-89.

Vrasidas, C. (2001). Constructivism versus objectivism: Implications for interaction, course design, and evaluation in distance education. International Journal of Educational Telecommunications, 6(4), 339-362.

Walmsley, C. J. (2004). Social representations and the study of professional practice. International Journal of Qualitative Methods, 3(4), Article 4. Retrieved August 22, 2006, from http://www.ualberta.ca/ iiqm/backissues/3_4/pdf/walmsley.pdf

Willinsky, J. (1989). Getting personal and practical with personal practical knowledge. Curriculum Inquiry, 19(3), 247-264.

Willis, J. (1998, May/June). Alternative instructional design paradigms: What's worth discussing and what isn't? Educational Technology, 38(3), 5-16.

\section{Acknowledgments}

This research is supported by a grant from the Social Sciences and Humanities Research Council of Canada.

(c) Copyright Katy Campbell, Richard A. Schwier and Richard F. Kenny [2006].

Please cite as: Campbell, K., Schwier, R.A., Kenny, R.F. (2006). Conversation as inquiry: A conversation with instructional designers. Journal of Learning Design, 1(3), 1-18. http://www.jld.qut.edu.au/ 